\title{
Identifying Potentiality Online Sales In Malaysia: A Study On Customer Relationships Online Shopping
}

Ahasanul Haque, (Email: ahasanul@iiu.edu.my), International Islamic University, Malaysia Javad Sadeghzadeh, (Email: sadeqzadeh@yahoo.com), Multimedia University, Malaysia Ali Khatibi, (Email: ali.khatibi@mmu.edu.my), Multimedia University, Malaysia

\begin{abstract}
Understanding of consumers buying pattern through internet and motivation of consumers to online shopping and what product has potential of online sales are critical questions. The purpose of this study was to identify the potential of online sales. The study started with verifying consumer online behavior and model of potential of online sales. The results showed only two factors, gender and family income was significant relationship with overall attitudes towards online shopping. In addition, results indicated that weekly internet use, having experience in e-shopping, and willingness to shopping online in the future have significant relationship with overall attitude towards online shopping. Moreover, results proved that there is significant difference between human senses in online decision-making process and it is explored to customers who experienced shopping a product or they were satisfied previously, which have stronger confidence to do online shopping. The estimation of Logistic model shows that potential of online sales is affected significantly by consumer overall attitudes towards online shopping, product type, familiarity and confidence.
\end{abstract}

\section{INTRODUCTION}

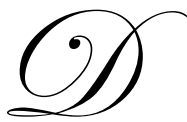

uring the 17th century, world experienced the industrial revolution, the way all the industries functioned was revolutionized. Now we are on the brink of a similar kind of a revolution since 1995.

The revolution can be attributed to the increasing use of the Internet in business. It has changed ways companies sell products to customers and distributes them to the retailers. Since Internet commerce has been developed, there were about 600 million online people in the world in 2002 (UNCTAD, 2002). The U.S department of commerce (2002) reported that more than half the US population was connected to the Internet in 2002. According to a study in Europe by Koichi, T (2002), e-commerce is poised to grow by nearly 50 percent per year. The total online retail revenue in Asia-Pacific has been $\$ 2.8$ billion in 2004, compared with $\$ 3.5$ billion in Europe, and $\$ 36.6$ billion in the US.

Many companies believe that there is money to be made as soon as the Internet becomes popular. In the retailers' opinion, the future of Internet shopping will always be bright however; nothing is guaranteed success for retailers and companies in e-commerce. Setting up a portal site is quite costly. It is one of the barriers hindering many investors in this field. Only when they offer appropriate goods and services for online channel, they can make sure that products will purchase by consumers. One of the critical arguments here is there any way that shows potential of online sales of a specific product? How many consumers are ready to buying online?

The general objective of this paper is to explore factors that affect potential online sales of a specific product. In short, this study investigates consumer online behavior, potential of online sales to identify those factors that influence online potential sales of a specific product. 


\section{LITERATURE REVIEW}

Consumer behavior in Internet shopping is widely used as the main concept of interests in a variety of studies. In a study by Donnavieve N. Smith and K. Sivakumar (2004), consumer behavior was explored based on the dimensions of flow facilities. Perceived risk, willingness to buy and consumer self confidence were investigate as a moderating factors in e-shopping behavior. Wolfinbarger M and Gilly M (2001) found that consumers shop to acquire items or shop to shop. Goal oriented motivation and experiential reasons are two main reasons for shopping. Charles Dennis, Harris L and Sandhu B (2002) found that Internet shopping is convenient but it is never replace actual shops. Internet shopping is not a personal experience because purchasers cannot try to see what they are buying and they are not very confident about giving credit card details over the Internet yet. Efthymios Constantinides (2004), analyzed the factors affecting online consumer behavior and examine how online marketing can influence the outcome of the virtual interaction and buying process by focusing their sales efforts on the elements shaping the consumer virtual experience and understanding their role in online consumer decision making.

Consumer behavior in traditional shopping contexts has received much attention, and a number of models of the buying process have been developed. A simple and often quoted model of the decision-making process associated with consumer buying is that proposed by Blackwell (2002). Based on the model a purchase process includes five stages: problem recognition, information search, evaluation of alternatives, purchase decision, and post-purchase support. Understanding of consumer behavior in this environment is limited since e-shopping is only just beginning to penetrate mass markets (Alan, D. et al., 2003 and Joshua Chang and Nicholas Samuel 2004). As activity in this market grows, researchers and social commentators will be interested to develop an understanding of the factors that affect consumer behavior in this marketplace.

According to the study by Shwu-Ing Wu (2003), a person's buying choices are influenced by four major psychological factors: motivation, perception, learning and beliefs and attitude and through motivation, perception, and learning, attitudes are formed and consumers make decisions. Some researchers categorized influence factors into internal and external factors (Kaufman-Scarborough K, 2002 and Shwu-Ing Wu, 2003). Based on this idea, consumer purchase behavior is influenced strongly by cultural, social, personal, and psychological characteristics. The internal factors are including beliefs and attitudes, learning, motives and needs, personality, perception, and values and the external influences upon consumer behavior includes demographic, economic, social, situational and technological factors. The lifestyle is between the external and internal influences on consumer buying behavior, because it truly involves elements of both.

\section{Potential Of Online Sales}

Developing e-sales strategy is started by asking companies what they want to sell and how they will sell it. From the electronic sales channel, some companies sell their whole product range, some just a few selected items. The critical question here will be is the product is suitable for online sales? Will customer buy it online? Many organizations are seeking to realize the potential of e-commerce and to engage in the e-marketplace (Rowley J, 2000). For companies operating at Internet being successful depends on identifying potential of online sales of their products. Not all goods have potential for selling electronically. Almost 50\% of advertisement costs are wasting (Michael et al. 2001), so if small and big companies unable to adopt a suitable strategy for selecting their relevant goods, which have enough potential for online sales, they may suffer heavy losses. So understanding which factors determine potential of online sales of a specific product in a particular market place is critical (Simpon Matthew 2001). Based on the different approaches, the influence factors can be categorized and defined as below:

\section{Demographic Characteristics}

There is strong empirical evidence that consumer personal characteristics influence the e-shopping preference and there are differences by gender, age, social grouping, and household income (Shwu-Ing Wu, 2003, Hung-Pin Shih, 2004, Edward Dube, 2001, Venkatesh Shankar, 2003, and Dryden J 2001). These are the things that consumers are or the way those individuals describe themselves and the way they label others. Consumer demographic characteristics, such as gender, age, or ethnic background, are examples of background characteristics. 
Behavioral processes are motivational, perceptual and learning, attitude formation, and decision-making tools consumers use to complete the activities that satisfy their needs (Hung-Pin Shih, 2004). A study identified the dimension of online shopping attribute and predictors of the intention to purchase clothes, jewelry or accessories based on online shopping attributes and demographic variable. The perceived attributes of online shopping consisted of four factors transaction/cost (gender, income and number of children), incentive program, site design and interactivity (Eun Young kim and Youn Kyung Kim, 2004). Unlike background characteristics, behavioral processes can be affected by a person's environment because they are applied on specific occasions. Marketers and public policy actors are particularly interested in these processes because they offer opportunities for them to exert their influence over consumers (Shwu-Ing Wu, 2003). A study conducted an approximation of the e-shopper profile and identifies the variables influencing purchase behavior. The methodology used to achieve these objectives is based on 7 focus groups and the analytical techniques of Chi-Square and logistic regression. Analysis of the results obtained from a representative sample of 2,104 Spanish Internet users shows that the M-commerce decision can be predicted according to consumer age, social class and behavior patterns as user of non-store shopping channels (Enrique Bigne et al., 2005).

\section{Product Type}

Designing the sales strategy based on the product characteristics could help explain the differences in the success of online retailing (Leo R Vijayasarathy, 2002). Previous empirical research on this subject has shown that customers do not prefer to shop online everything. Although, it may appear to be attractive to sell to consumers online, it may also present e-retailers with a range of problems. Only some products are suited for electronic markets because they not only take advantage of the digitization of the market mechanism, but also the distribution mechanism, resulting in very low transaction costs (Simpson Poon S and Joseph M, 2001). Product characteristics also are an important part of purchasing decision and consumer behavior models (Degeratu, A. et al., 1999). In a study by Rowley J (2000), it was investigated that tangibility is major factor to explain differences between Internet shopping intentions for products categorized. Based on these concepts, products have own set of characteristics, which relate to the five human senses of sight, sound, smell, taste, and touch. Products, which traditionally need to be taught, tasted, or smelled are prima facie less likely to sell well online. Tonita Perea y Monsuwe et al., (2004), research conducted for understanding consumer attitude towards online shopping and their intention to shop on the internet. The framework uses and constructs of the Technology Acceptance Model (TAM) as a basis extended by exogenous factors and applied into the online shopping context. The review showed that attitude towards online shopping and intention to shop online are not affected ease of use, usefulness and enjoyment but also exogenous factors like consumer traits, situational factors, product characteristics, previous online shopping experience and trust in online shopping.

\section{Familiarity and Confidence}

Familiarity and confidence are two important factors influencing e-shopping preference and potential of online sales. Familiarity of consumers with a product is created when there are successful sales history, strong brand image and customer satisfaction (Michael De Kare Silver 1999 and Kevin S Krug; Charles A Weaver 2005), Confidence is derived from consumers' attitudes and directly influences' intentions to purchase online (Donnavieve N Smith and K Sivakumar, 2004). Degeratu, A.M. and Arvind Rangaswamy (1998) argued that, company brand names become more important online in some category than offline. Brand name is more valuable where information on fewer attributes is available online. Rowley, J (2000) reported that brand name is one of the nine attributes appear relevant for characterizing various online retailers. These are geography, accessibility, atmosphere, service/experiential, convenience, speed of acquisition, brand name, assortment, security, information availability, and customization/personalization. Coltman, T. et al., (2000) suggested two reasons for brand attractiveness: (1) brand names can act as substitutes for information gathering, helping online buyers locate specific products, reducing search costs, and (2) brands build trust, security and an expectation regarding product quality. Brand familiarity, makes consumers be able to trust to online sales channel and feel more comfortable through internet. In addition, customers who recently purchased a product they are more likely to do next purchase online than whom intent to shop a product for first time (Dirk Van den Poel and Wouter Buckinx, 2004). A study found that, the frequency of past purchases is positively related to a customer's buying behaviour. 


\section{Consumer Attitude towards E-shopping}

Attitude is defined as a person's relatively consistent evaluations, feelings and tendencies toward an object or idea (Ellen Gordon M and De Lima-Turner, 1997). Clear realizing consumer attitudes toward online shopping can help marketing managers predict the online shopping rate and evaluate the future growth of online commerce. Clear understanding what motivates consumers to shop online can and should help in formulating strategy, technology and marketing decisions as well as website design (Wolfinbarger M and Gilly M, 2003). Intention of investigating consumer attitudes in fact in seeking answer of this question that what sort of consumer typically buys online products and what is their attitude to buying online? This means that there is no point having an excellent online product if the sort of people who would buy it and unlikely to be online. In a situation, appropriate to e-shopping environment if the product's characteristics have electronic appeal and the consumers are familiar and confident in buying then eshopping potential may be low. Actually, it cased when consumers prefer to visit the store not shopping online. Alternatively, they may switch from ever visiting the store and ultimately reduce the profit margin of the physical store. Therefore, before starting e-sales strategy it is critical considering consumers attitudes towards online shopping because of e-retailers group with the higher attitude score should be target market (Shwu-Ing Wu, 2003). Different studies have been mentioned various types of consumers based on their shopping attitudes. Based on the study by Kalakota and Whinston (1999) consumers characteristics are classified as either impulse, patient or analytical. According to a classification by Brynjolfsson E and D. Smith (1999), consumers can be categorized into three groups: (1) Frenzied copers (2) Habitual die-hards and (3) Mercenaries. In another consumer classification by Michael De Kare Silver (1998), customers has been categorized based on their shopping behavior into six groups: (1) Social shoppers (2) Experimenters (3) Convenience Shoppers (4) Habit-bound die-hards (5) Value shoppers (6) Ethical Shoppers.

\section{E-shopping Environmental Characteristics}

To do shopping online some situation must be provided. Positive consumer attitudes towards online shopping even following by intention to buy a well-known branded product may not be enough to doing shopping online. Indeed initially, the level of e-shopping is strongly related to the level of internet access (MORI, 2001). Those shoppers who unable to afford to get internet access they cannot afford to be e-shoppers. Furthermore, lake of appropriate Internet access speed may cause to e-shopping failure. Beside this, e-shopping awareness is another factor that influences e-shopping. The consumers with substantial levels of internet access only with a high level of awareness of what the internet has to offer, are real e-shoppers. For marketer the group with the higher internet familiarity score should be the target market (Shwu-Ing Wu, 2003). It is logical to infer that e-business would be especially suited to the marketplaces where high level of internet access with other appropriate conditions. Environmental situation influence s-shopping familiarity where the consumer experienced e-shopping before (KeeSook Lim, 2002). In general, knowledge of the customer on the computer and the internet and frequency and length of his/her usage, were found to be positively associated to adoption behaviour (Man Kit Chang and Waiman Cheung and Vincent S. Lai, 2005). Furthermore, other factors such as poorly designed interfaces, cluttered page layouts, inadequate and ineffective search engines, dead links, outdated information, tedious navigational structures, and complex checkout procedures may all contribute to consumer frustration with online shopping (Leo R. Vijayasarathy, 2002). Marie-Odile Richard and Ramdas Chandra (2005), the author explore the relationship of the model of the consumer response to website and interface characteristics. The conceptual model of the web navigation model behavior was organizing various literature reviews into three main parts such as personal factors, situational factors and outcomes. Based on their study proposed model constitutes of five main components, a) ability of process which include challenge, skills and interactivity b) personal factors of the web navigation, include reason, need for cognition and optimum stimulation level c) situational factors of the web navigation includes site involvement, exploratory behavior and attitude towards site d) effectiveness of web navigation include cues and e) outcome including prepurchase intention. 


\section{RESEARCH METHODOLOGY}

\section{Conceptual Foundation And Framework}

This study concentrates on conceptual framework of consumer online behavior and e-shopping. This framework emphasizes those variables, which affect potentiality of online sales to specific product. Research framework and conceptualization of the relationship between potential of online sales and affective factors are constructed in the Figure 1. This particular framework shows that potential of online sales is influenced by three factors including consumer attitudes, product type and familiarity of consumer to the product. In addition, demographic characteristics and environmental characteristics influence consumer attitude towards online shopping and entered into the model as controlling factors. Product type is affected by human sensory attributes. Moreover, familiarity \& confidence to the product is influenced by brand name, shopping experience, and satisfaction. The hypotheses of the study are constructed in order to establish the relationships between factors.

\section{Hypotheses}

$\mathbf{H}_{1}$ : The consumer attitude towards online shopping is not statistically significantly different based on consumer demographic characteristics.

$\mathbf{H}_{2}$ : The consumer attitude towards online shopping is not statistically significantly different based on e-shopping environment.

$\mathbf{H}_{3}$ : There is no significant difference between influences of human senses in online shopping.

$\mathbf{H}_{\mathbf{4}}$ : There is no significant relationship between shopping experience and familiarity \& confidence in online shopping.

$\mathbf{H}_{5}$ : There is no significant relationship between satisfaction and familiarity \& confidence in online shopping.

$\mathbf{H}_{6}$ : There is no significant relationship between customers' attitude towards online shopping and potential of online sales.

$\mathbf{H}_{7}$ : There is no significant relationship between product type and potential of online sales.

$\mathbf{H}_{8}$ : $\quad$ There is no significant relationship between familiarity \& confidence and potential of online sales.

Figure 1: Research Framework

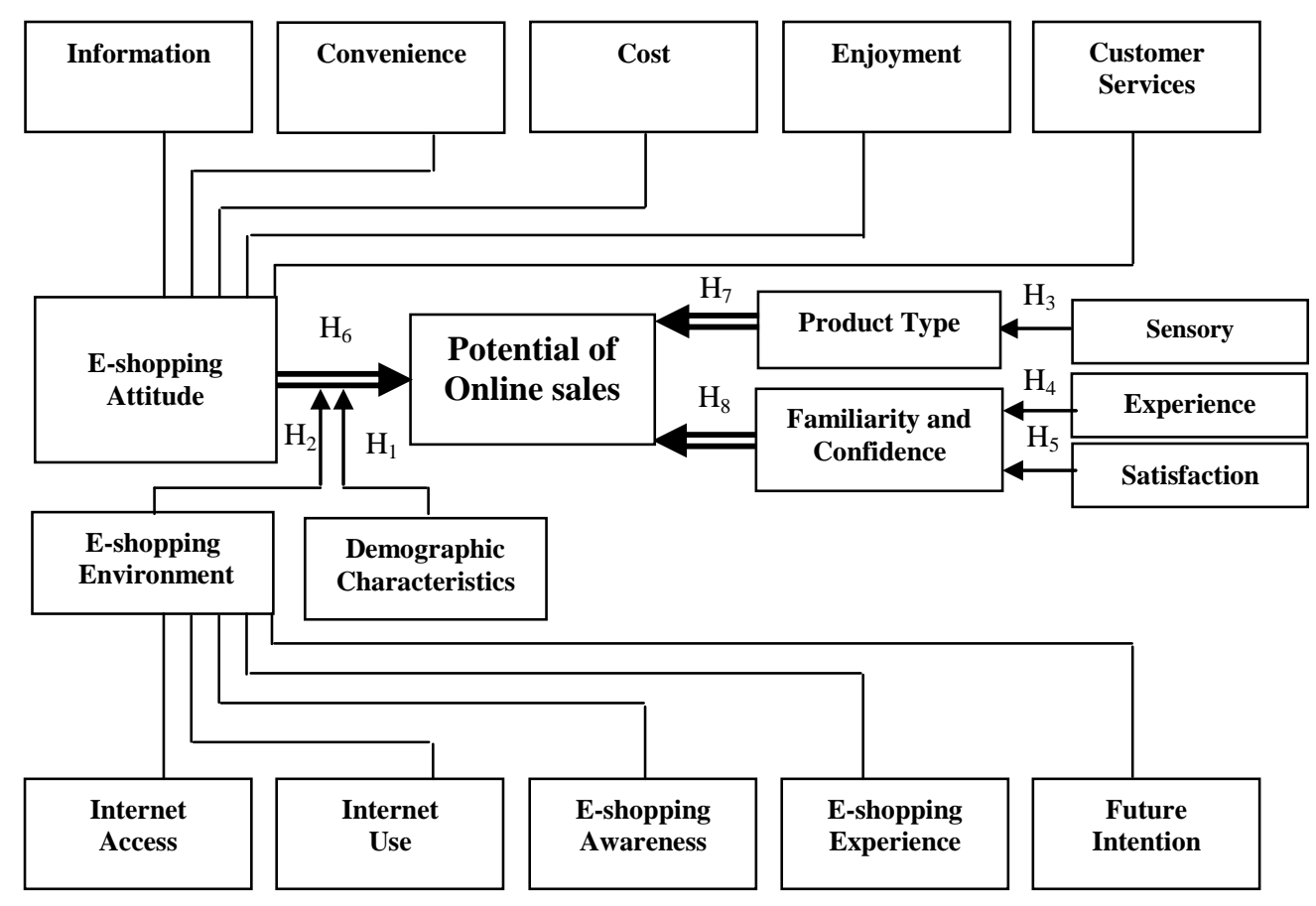



model.

For hypothesis testing, overall consumer attitude towards online was measured by Fishbeins' behavioural

\section{Fishbein's Behavioral Model}

Measuring attitude in survey studies are widely used in different researches today. Fishbein's behavioural model is one of the most influential and widely researched models about attitude (Shwu-Ing Wu, 2003). According to the Fishbein's model, attitudes of people are formed toward a specific object based on their beliefs (perceptions and knowledge) about these objects. Fishbein's model was constructed to measure person's overall attitude toward some object and could be derived from his beliefs and feelings about various attitudes about the object. This model can thus be used as a multi attribute attitude measurement model. In this study five attributes namely, convenience, information, speed, enjoyment, and customer service were chosen to measure consumer overall attitude towards online shopping. Fishbein's attitude model can be expressed in equation form as:

$$
A_{o}=\sum_{i=1}^{n} b_{i} e_{i}
$$

Where: $A o=$ the person's overall attitude toward object o. $b i=$ the strength of his belief that the object is related to attribute i. $e i=$ evaluation or intensity of feelings toward attribute i. $n=$ the number of relevant beliefs for that person.

\section{Logistic Model}

In order to investigate relationships in potential of online sales, a Logistic model was developed. As the potential of online sales it is probability in nature and changing between zero and one, so it appropriately treated as a binary or two choices variable the following Logistic equation was estimated.

$$
L_{i j}=B_{i j}+B_{i j 2} \cdot P C_{i j}+B_{i j 3} \cdot C A_{i j}+B_{i j 4} \cdot F C_{i j}
$$

\section{Data Collection}

A structure questionnaire was used to collect the necessary data which served as primary data to answer the research questions and objective regarding identified potentiality online shopping in Malaysia. The survey question consists six specific sections and each of contain question pertaining different part of the study. In view of the time and cost constraints and Difficulty of access to the airline ticket customers in Malaysia caused to conduct convenience sampling method was used for data collection procedures. Therefore, some specific places were chosen for distributing the questionnaires. It was mainly the KLIA (Kuala Lumpur International Airport) and some airline agencies in Kuala Lumpur Klang Valley area which is indicating highest concentration of internet users. The survey was conducted mainly via face-to-face interview and also administrated through e-mail and postage service. A list of e-mail users was obtained from Telekom Malaysia who currently registered with TMNet and survey questionnaire was only e-mailed to those internet users agreed to participate in the survey. This step was taken mainly to avoid complains from the internet user and also to increase number of respondents. Apart from ability to reach large target respondents and inexpensive way to conduct the survey, the survey through e-mail also enabled respondents to perform easily provide extensive responses to open ended questions was provided valuable input to the study for better understanding online shopping in Malaysia. Beside e-mail, the survey questionnaire was posted on the UseNet group and only those related to Malaysia were used. Total 450 questionnaires were distributed, and each of the responses received was screened properly for error, incomplete and missing responses. Efforts were also taken to contact the affected respondents through e-mail for clarification and correction, especially for missing and blanks responses. However, those responses that had more than $20 \%$ of the questions in the survey questionnaire that have been left unanswered or incorrectly answered were deducted from data analysis. After the screening process was carried out 68 considered as unusable and rest 382 responses which were considered complete and valid for final analysis and hypothesis testing. 


\section{RESULTS AND DISCUSSION}

The age distribution of respondents showed that mean age was 35 years old while minimum age was 17 and maximum age was 56 . The gender distribution of the respondents was $77 \%$ males and $23 \%$ females. Most of the respondents reported that they were graduate $(23.3 \%)$, followed by $22.3 \%$ certificate, $20.2 \%$ post graduate, $21.5 \%$ STPM diploma, and $8.6 \%$ were SPM. In the case of the race, $58.6 \%$ of the respondents were Malay, $24.3 \%$ Chinese and $14.1 \%$ Indians. Also nearly $75 \%$ of respondents were married and the rest $25 \%$ were single. Regarding to the respondents' job, the largest group belong to government servant $(23.6 \%)$, followed by private sector professionals (20.7\%), businessmen in IT fields (19.9\%), businessmen in non IT fields (17.3\%), student (9.7\%) and others (8.9\%). In the term of the family income, families with MR 3000 to RM 3500 per month were the largest group among the respondents (22\%) then families with more than RM 5000 (13.1\%). Also 6.5\% of respondents reported that they earn less than RM 1000 per month. Furthermore, 90\% of respondents had access to the Internet, $87 \%$ were aware of eshopping but $72.3 \%$ have not had any experience in e-shopping. Along with this, $30.4 \%$ said they will purchase online in next twelve months.

\section{Demographic Characteristics Of Respondents}

Analysis of variance was conducted to investigation relationships between overall consumer attitudes towards online shopping and consumer demographic characteristics $\left(\mathrm{H}_{1}\right)$. Table 1 shows analysis of variance results for customer demographic characteristics. According to the results with $95 \%$ confidence, two factors of gender and family income have significant relationship with overall attitude towards online shopping $(\mathrm{P} \leq 0.05)$.

Table 1: Analyses Variance For Consumer Demographic

\begin{tabular}{|c|c|c|}
\hline Descriptions & $\mathbf{F}$ & Sig. \\
\hline (1) Age & 2.468 & 0.062 \\
\hline (2) Gender & 8.000 & 0.015 \\
\hline (3) Education & 0.746 & 0.604 \\
\hline (4) Marital Status & 0.000 & 1.000 \\
\hline (5) Job & 0.260 & 0.898 \\
\hline (6) Family Income & 3.423 & 0.044 \\
\hline (7) Race & 1.778 & 0.205 \\
\hline
\end{tabular}

\section{Analysis Of E- shopping Environment}

Testing hypothesis $\left(\mathrm{H}_{2}\right)$ showed that three factors including: weekly internet use, e-shopping experience and willing to e-shopping in future have significant relationship with overall consumer attitude towards online shopping $(\mathrm{P} \leq$ 0.05). Also with $90 \%$ confidence there was significant relationship between overall attitudes towards online shopping and experiences $(\mathrm{P} \leq 0.1)$. Analysis of variance did not show any significant relationship for other factors.

Table 2: Analyses Variance For Environment Characteristics

\begin{tabular}{lcc}
\hline \multicolumn{1}{c}{ Descriptions } & F & Sig. \\
\hline (1) Internet Access & 0.078 & 0.780 \\
(2) Internet Use & 3.932 & 0.002 \\
(3) E-shopping Awareness & 0.002 & 0.966 \\
(4) Having E-shopping experience & 6.441 & 0.012 \\
(5) Number of Previous E-shopping & 2.201 & 0.088 \\
(6) Willingness to Further Purchase & 6.031 & 0.003 \\
\hline
\end{tabular}




\section{Analysis Of Product Type}

This hypothesis constructed to investigate whether applicability of human senses are significantly different in online shopping $\left(\mathrm{H}_{3}\right)$. Human senses were categorized then based on the virtual online space. The Friedman Test was used to test significantly differences of ranking human senses (Table 3). Results showed with 95\% confidence there is significant difference in human senses in online shopping. So $\mathrm{H}_{3}$ was rejected.

Table 3: Friedman Test Of Ranking Human Senses In Online Shopping

\begin{tabular}{cc}
\hline Statistic & Value \\
\hline $\mathrm{N}$ & 382.000 \\
Chi-Square & 776.407 \\
Asymp. Sig. & 0.0 \\
\hline
\end{tabular}

Table 4 shows ranking result of effectiveness of human senses. According to the table, products which need sense of sight to be chosen online are more likely to be sold online followed by sense of sound, sense of smell, sense of taste and sense of touch.

Table 4: Online Shopping Virtual Ranking Of Human Senses

\begin{tabular}{lc}
\hline \multicolumn{1}{c}{ Human Sense } & Mean Rank \\
\hline Sense of sight & 1.69 \\
Sense of sound & 2.32 \\
Sense of smell & 3.14 \\
Sense of taste & 3.75 \\
Sense of touch & 4.10 \\
\hline
\end{tabular}

\section{Analysis Of Familiarity \& Confidence}

Where consumers already know the product brand name and have purchased it before and been satisfied with their experiences, familiarity and confidence for e-shopping is higher. For testing hypotheses $\mathrm{H}_{4}$ and $\mathrm{H}_{5}$, Malaysian Airline ticket was used as the example. The respondents were asked to report their familiarity with Malaysian Airline and their previous shopping and satisfaction. Chi-Square test and Spearman correlation were used to investigation significantly of relationships between these variables (Tables 5 and 6).

Table 5: Correlation Analyses Among Familiarity, Confidence, And Satisfactory

\begin{tabular}{|c|c|c|}
\hline Test & & Value \\
\hline Chi-Square & Statistic & 94.661 \\
\hline \multirow{4}{*}{ Spearman Correlation } & Sig. (2-tailed) & 0.000 \\
\hline & Correlation Coefficient & 0.266 \\
\hline & Sig. (2-tailed) & 0.015 \\
\hline & $\mathrm{N}$ & 83 \\
\hline
\end{tabular}

The results approved that where consumer purchased a product and especially if he/she satisfied of previous purchase, familiarity and confidence of consumers to purchase the product online is increased. 
Table 6: Correlation Analyses Among Familiarity, Confidence, And Experience

\begin{tabular}{ccc}
\hline Test & & Value \\
\hline Chi-Square & Statistic & 109.578 \\
& Sig. (2-tailed) & 0.000 \\
Spearman Correlation & Correlation Coefficient & -0.464 \\
& Sig. (2-tailed) & 0.000 \\
& $\mathrm{~N}$ & 382.000 \\
\hline
\end{tabular}

\section{Logistic Model Of Potential Of Online Sales}

This study proposed to identify factors affecting potential of online sales of a specific product. The three hypotheses of the study $\left(\mathrm{H}_{6}, \mathrm{H}_{7}\right.$, and $\left.\mathrm{H}_{8}\right)$ were constructed in the way that three main factors influence potential of online sales. These factors were overall consumer attitude towards online shopping, product type and familiarity and confidence of consumers with a product. For testing the main hypotheses of this study Logistic model was developed. The dependent variable was the potential of online sales that takes 1 when product has bought online and 0 when product has bought offline. The Logistic equation was:

$$
L_{i j}=B_{i j}+B_{i j 2} \cdot P C_{i j}+B_{i j 3} \cdot C A_{i j}+B_{i j 4} \cdot F C_{i j}
$$

PC refers to product type, CA refers to consumer overall attitude towards online shopping and FC refers to familiarity and confidence. Out of 382 questionnaires only 83 respondents traveled by Malaysian Airline and the rest have not bought Malaysian airline ticket so 83 data were used for estimating process. The estimation result is shown in table 7. According to the results with $95 \%$ confidence, all coefficients were significant. It is mean that potential of online sales has significant relationship with the variables. The constant coefficient of the equation also was significant in same confidence level. The negative value of the variable PC (Products type) indicates that when the dependency of choosing a product to human senses increases, potential of online is decreased. The estimated equation was:

$$
\mathrm{L}=(-4.697)+(0.093) \mathrm{CA}+(-1.525) \mathrm{PC}+(0.817) \mathrm{FC}
$$

$$
\begin{array}{llll}
(2.212) & (0.037) \quad(0.579) & (0.314)
\end{array}
$$

Table 7: Estimation Of Coefficient Of Logistic Equation

\begin{tabular}{cccccc}
\hline Variables & B & S.E. & Wald & df & Sig. \\
\hline CA & .093 & .037 & 6.352 & 1 & .012 \\
FC & .817 & .314 & 6.761 & 1 & .009 \\
PC & -1.252 & .579 & 4.678 & 1 & .031 \\
Constant & -4.697 & 2.212 & 4.512 & 1 & .034 \\
\hline
\end{tabular}

With referee to the potential of online sales model, the paper started with testing sub-hypotheses of the study. The first sub-hypothesis which tested was significantly of relationship between consumer attitudes towards online shopping and consumer demographic and environment characteristics. The results show that the relationship was significant for some factors. Using analysis of variance and overall attitude mean with $95 \%$ confidence and result showed that only two factors, gender $(\mathrm{F}=8.0, \mathrm{P} \leq .05)$ and family income $(\mathrm{F}=3.423, \mathrm{P} \leq .05)$ had significant relationship with overall attitude towards online shopping $(\mathrm{P} \leq .05)$. It reveals that overall attitudes of families with higher income are higher than others. In addition, men have stronger attitudes to online shopping compared with women. 
Analysis of variance of overall attitude towards online shopping and environment characteristics showed there is no any significant relationship between internet access and overall attitudes towards online shopping but weekly internet use $(\mathrm{F}=3.932, \mathrm{P} \leq .05)$, e-shopping experience $(\mathrm{F}=6.441, \mathrm{P} \leq .05)$, and intention to further online shopping $(\mathrm{F}=6.031, \mathrm{P} \leq .05)$ have significant relationship with overall attitude towards online shopping. The third subhypothesis was about investigating significant differenced between human sensory attributes. Using Freidman test we found that virtual human senses are applicable in e-shopping. The last two sub-hypotheses were about testing relationship between familiarity and confidence and experience and satisfaction. It was explored that customers who experienced shopping a product weather online or offline $(\mathrm{F}=109.578, \mathrm{P} \leq .05)$ or satisfied with their experience $(\mathrm{F}$ $=94.661, \mathrm{P} \leq .05)$, have stronger familiarity and confidence to online shopping.

The estimation of Logistic model shows with 95\% confidence all coefficients were significant. It means that potential of online sales has significant relationship with overall attitude towards online shopping ( $\mathrm{Sig}=.012)$, product type ( $\mathrm{Sig}=.031)$ and familiarity and confidence $(\mathrm{Sig}=.009)$. The negative value of the variable PC (Products type) indicated that in online shopping when consumer has to apply physical human senses such as touch and taste, potential of online sales will be reduced.

\section{CONCLUSION AND IMPRECATIONS}

This study is to examine and understand the profiling characteristics of current users of identifying potentiality online sales and investigating the relationships between potential of online sales and affective factors respecting to objectives of the study. The major findings of the study indicated that demographic characteristics were including age, gender, educational level, marital status, job, family income and race. Using ANOVA and overall attitude mean with 95\% confidence level and resulted are only two factors such as gender and family income had significant relationship with overall attitude. It reveals that overall attitude of families with higher monthly income are higher compared to other attributes such as educational level, race and marital status did not show any significant relationship with overall motivation in this respect. Results also highlighted from ANOVA, the overall attitudes towards online shopping and environment characteristics and there is no any significant relationship between internet access and overall attitudes towards online shopping but weekly internet use having in e-shopping and willingness to more shopping online have significant relationship with overall attitudes online shopping. It means internet access rate is high among peoples but few percentages have intention for e-shopping.

In addition, results of this study investigated significant differences between human senses in e-purchasing process. Using Freidman test and analyzed when consumer have willingness to choose a product online, they refer to human senses in online purchasing and it has significance different. So result proves that there is a significant difference between human senses in online decision making process. Moreover, results concluded from Logistic model and showed strong relationship among the three independent variables with dependent variable which belong to brand familiarity, product types and consumer attitudes for online shopping. These results are significantly different from the electronic shopping test in which attitudes towards online shopping have the strongest influence on eshopping possibility. Also depart from estimation of the Logistic model and verified that companies present physical product online but need to gain the advantages of famous brand name and sales experience are likely to be successful than those companies offer virtual products without familiar brand name and are new in the market.

Implications can be derived base on findings which are produced and divided into three parts, namely, for online retailers, Telekom Malaysia as the main telecommunication and internet service provider in this country and the Government of Malaysia. For online retailers need to ensure that online shopping process through their website is designed and made as easy, simple, and convenient as possible. The web site should also be designed in such way not to confuse potential Malaysian buyers, those who are generally not familiar with this new form of shopping. They should ensure that they provide an efficient delivery service to their customers. In addition, need to develop a privacy policy for their customers on discloser of personal informations in order to lessen their concern for privacy. In line with this vision, strategic direction and business objectives, it is imperative for Telekom Malaysia to take up a major role in leading the country towards an e-commerce era. As leading telecommunication and internet service provider in this country, Telekom Malaysia needs to provide cheaper internet access in order to encourage more consumers to become internet users. This is to accelerate the growth on internet user in Malaysia with the intention to create a 
critical mass online shopper in Malaysia. Introduce more affordable high-speed internet access to cater online customers who require high bandwidth in the delivery of digitized products such as computer software, music, videos and games through the internet, which are presently popular and frequently purchased by users of internet shopping. In spite of that, government has taken several key steps in supporting and promoting the growth of e-commerce in this country, nevertheless they can till pay their role especially in accelerating the development of retail e-commerce, which are currently lacking compared to other developed nations. In this respect, the Government needs to establish commercial codes that government commercial transactions between business and consumers through the internet. These commercial codes and practices that cover various aspects of internet shopping including consumers privacy, security and resolution of disputes. In fact, the potential of e-shopping will get significant privilege when customers will show less traditional culture and shopping behavior attitude.

Some limitations drown from this study, which indicated one-time measurements for data collection, limited questionnaires and time constraints of the survey. The sample obtained by the survey instrument which presents some challenges due to insufficient informations. As Malaysian people have been chosen as population of this study, convenience sampling method may not be able to gather a comprehensive sample of population. In addition, KLIA (Kuala Lumpur International Airport), Kuala Lumpur (within Klang Valley) in Selangor estate is not represented of all Malaysian air ticket market. Moreover, this study highlighted mainly the relationship between potential of online sales and overall consumer attitude towards internet shopping, product type, e-shopping environment, brand familiarity and confidence to repeat purchasing was investigated. However, this study did not mention the relationship between the potential of online sales and some other factors such as delivery and prices. Nevertheless, it is hope that such limitations could suggest and encourage additional directions and guidelines for further study.

\section{REFERENCES}

1. Alan D. Smith and William T. Rupp; (2003). Strategic online customer decision making: leveraging the transformational power of the Internet; Online Information Review; Vol. 27 (6): 418-432.

2. Blackwell, R.D., Miniard, P.W., and Engel, F (2002) Consumer Behavior, $9^{\text {th }}$ edition South-Western, Thomson Learning.

3. Brynjolfsson, E and Michael D. Smith, (1999). Frictionless Commerce? A Comparison of Internet and Conventional Retailers, Management Science Vol. 46 (4) 563-585.

4. Charles Dennis, Lisa Harris, and Balraj Sandhu, (2002). From Bricks to Clicks: Understanding the Econsumer, Qualitative Market Research - An International Journal, Vol. 5 (4): 281-290.

5. Coltman, T., Timothy M Devinney, and Alopi Latukefu (2000). E-Business: Revolution or Hype? Working paper, Australian Graduate School of Management, Sydney, pp. 1-37.

6. Degeratu, A. M., Arvind Rangaswamy, and Jianan Wu (1999). Consumer Choice Behavior in Online and Traditional Supermarkets: The Effects of Brand Name', Price, and Other Search Attributes, International Journal of Research in Marketing, Vol.17 (1): 55-78.

7. Dirk Van den Poel and Wouter Buckinx (2004). Predicting online-purchasing behaviour; Working Paper, Faculty of Economics and Business Administration, Ghent University, Belgiu, 03/195.

8. Donnavieve N. Smith and K. Sivakumar, (2004). Flow and Internet Shopping Behavior: A Conceptual Model and Research Propositions, Journal of Business Research, Vol. 57 (10): 1199-1208.

9. Dryden, J (2001). Consumers in the Online Marketplace, OECD Workshop, Berlin, 13-14, March 2001.

10. E-commerce Development Report, UNCTAD, 2002.

11. Edward Dube and Richard Benedetto (2001) E-commerce Success.

12. Efthymios Constantinides (2004). Influencing the online consumer's behavior: the web experience, Internet Research, Vol. 14 (2): 111-126.

13. Ellen Mary Gordon and Kathryn De Lima-Turner, (1997) Consumer attitudes towards Internet advertising: A social contract perspective, International Marketing Review, Vol. 14 (5):362-375.

14. Enrique Bigne, Carla Ruiz, and Silvia Sanz (2005). The impact of internet user shopping and demographics on consumer mobile buying behaviour, Journal of Electronic Commerce Research, Vol. 6 (3): 193-209.

15. Eun Young Kim and Youn Kyung Kim (2004). Predicting online purchase intentions for clothing products, European Journal of Marketing, Vol. 38 (7): 883-897. 
16. Hung-Pin Shih, (2004). An empirical study on predicting user acceptance of e-shopping on the Web, Information and Management, Vol. 41 (3): 351-368.

17. Joshua Chang and Nicholas Samuel (2004). Internet Shopper Demographics and Buying Behaviour in Australia, Journal of American Academy of Business, Cambridge, Vol. 5 (1\&2): 171-176

18. Kalakota, R and Whinston, M (1999). E-Business - Roadmap for success, Addition Wesley, $1^{\text {st }}$ Edition

19. Kaufman, C. Scarborough, (2002). E-shopping in a multiple channel environment, Journal of Consumer Marketing, Vol. 19 (4): 333-350

20. Kee-Sook Lim, (2002). Security and motivational factors of e-shopping website usage, Decision Science Institute, Annual Meeting Proceedings.

21. Kevin S Krug and Charles A Weaver (2005). Eyewitness Memory and Metamemory in Product Identification: Evidence for Familiarity Biases, The Journal of General Psychology, Vol. 132 (4): 429-445

22. Koichi Tonegawa (2002) A review and analysis: E-commerce research forum 1998-2001, working paper for ERF at MIT

23. Leo R. Vijayasarathy, (2002) Product characteristics and Internet shopping Intentions, Internet Research: Electronic Networking Applications and Policy, Vol. 12 (5): 411-426.

24. Man Kit Chang, Waiman Cheung, and Vincent S. Lai; (2005). Literature derived reference models for the adoption of online shopping; Information and Management, Vol. 43 (4): 543-559

25. Marie-Odile, Richard and Ramdas Chandra (2005). A model of consumer web navigational behavior: conceptual development and application, Journal of Business Research, 58: 1019-1029

26. Michael D. Smith and Erik Brynjolfsson, (2001). Consumer Decision-making at an Internet Shopbot, MIT Sloan School of Management Working Paper No. 4206-01 http://www.ebusiness.mit.edu.

27. Micheal de Kare Silver, (1998). E-shock the electronic shopping revolution: Strategies for retailers and manufactures, London, Mac Millan Business

28. MORI, (2001) Informing Customers About E-shopping: Qualitative Survey Report

29. Rowley, Jennifer, (2000). Product search in e-shopping: a review and research propositions, Journal of Consumer Marketing, Vol. 17 (1): 20-35

30. Rowley, Jennifer, (2000). Product searching with shopping bots Internet Research: Electronic Networking Applications and Policy, Vol.10 (3): 203-214

31. Shwu-Ing Wu, (2003). The relationship between consumer characteristics and attitude toward online shopping, Marketing Intelligence and Planning, Vol. 21 (1): 37-44

32. Simpson Poon and Mathew Joseph, (2001). A preliminary study of product nature and electronic Commerce, Marketing Intelligence \& Planning, Vol. 19 (7): 493-500

33. Tonita Perea Y Monsuwe, Benedict G C Dellaert, and Ko De Ruyter (2004). What drives consumers to shop online? A literature review, International Journal of Service Industry Management, 15 (1): 102-121

34. Venkatesh Shankar, Amy K. Smith, and Arvind Rangaswamy, (2003). Customer Satisfaction and Loyalty in Online and Offline Environments, Journal of Research. Marketing Vol. 20 (2): 153-175

35. Wolfinbarger, Mary and Mary Gilly, (2001). Shopping Online for freedom control and fun, Vol. 43 (2): $34-$ 55 